\title{
Time to change: the Fragility Fracture Crisis
}

\author{
M A Fernande $z^{1,2 *}$ and M Costa ${ }^{1}$
}

${ }^{1}$ Oxford Trauma, University of Oxford, Kadoorie Centre, John Radcliffe Hospital, Headley Way, Oxford OX3 9DU, UK

${ }^{2}$ University Hospitals Coventry \& Warwickshire NHS Trust, Clifford Bridge Road, Coventry, CV2 2DX, UK

\section{*Corresponding author}

"An older person suffering a fall from standing height is now the commonest type of major trauma in the national database".(1) This observation in the 2017 UK TARN report on major trauma reflects a stark change in the epidemiology of fragility fractures and has profound consequences for healthcare systems around the world. Rapid action is required if we are to meet what is likely to be a sustained and unrelenting increase in the volume and complexity of trauma cases in older patients.

The burden of disease is massive. In the year 2000 there were an estimated 9 million new fragility fractures worldwide and 50 million people living with the consequences of these injuries.(2) We know that sustaining a hip fracture has a profound and long lasting effect on quality of life persisting beyond 1-year post injury.(3) The associated costs are staggering - in Europe alone the estimated costs of fragility fracture care were $€ 37$ billion in 2010.(4) This burden of disease and associated health and social case cost is set to increase exponentially. We are witnessing an unprecedented demographic shift; a shift towards an older, frailer but still active adult population. The so called "longevity miracle". We are beginning to observe this effect on the epidemiology of fragility fractures and major trauma in Europe, but the impact in Asia Pacific and South America has yet to be realised. The term 'silver trauma', whilst not welcomed by all, acknowledges this demographic shift and brings with it the current reality that trauma in the elderly has worse outcomes and increased mortality compared with similar injuries in younger people.(1) A recent prospective cohort study also reflects the increasing incidence of complex fracture patterns, open fragility fractures, and older adults with multiple fractures.(5) This 
increasing burden and complexity of injuries mean that societies and healthcare systems are heading towards a potential crisis with unprecedented demands on resources. Our ability to meet these challenges will depend on improvements in a number of areas not least: multi-disciplinary acute care, rehabilitation and secondary fracture prevention. These will involve changes in the way in which we coordinate and deliver care both in and out of hospital.(6) We will need high quality data, including national registries. Research in these areas has also been highlighted as a priority by the patients themselves in a recent national research priority setting exercise.(7)

The UK NICE osteoporosis guideline(8) states that "fracture risk is currently assessed opportunistically" and more efficient ways are required to identify atrisk patients for assessment and possible treatment. This is particularly so for high-risk groups who are difficult to access such as those with cognitive impairment in nursing homes. Of course, the most effective primary prevention strategies begin in adolescence with interventions aimed at improving peak bone mass in young adults. Epidemiological studies project that a $10 \%$ increase in peak bone mass would result in a 50\% reduction in the risk of fracture in later life.(9) We know that of the modifiable factors that increase bone mass, physical activity and dietary intake have the most evidence(9) - justification, if ever it was needed, to tell our children to put down the games consoles and do more exercise.

The fracture liaison service model of secondary prevention has proven to be effective but it is not delivered everywhere and there exists a global 'treatment gap'.(10) The UK has led the way in post hip fracture secondary prevention with the implementation of Fracture Liaison Services and the 'best practice tariff' as part of the largest ongoing audit of hip fracture care in the world - the National Hip Fracture Database (NHFD).(11) Hip fracture has become a 'marker' condition for fragility fracture care but the NHFD standardised treatment pathways and key performance indicators are not necessarily applied to other severe fragility fractures such as fractures of the distal femur and fragility fractures around existing implants (periprosthetic fractures). There is no justification for these injuries being treated differently from hip fractures. Improvements in all areas of fragility fracture care are vital if we are to continue 
to advance quality of care for patients, whilst coping with the projected increased workload.

The Global Fragility Fracture Network (FFN) has coordinating a Call to Action to meet these challenges.(12) This call has been endorsed by over 80 international organizations and has led to the development of national Fragility Fracture Networks in over 20 countries, representing half the world's population The express mission of the national FFN's is to change policy in each of those countries, with the aim is to improve the multidisciplinary acute management of patients with a fragility fracture, to improve rehabilitation services for these vulnerable patients and to implement effective secondary prevention strategies. For this to happen, leaders in nursing, anaesthetics, orthopaedics, rheumatology, geriatrics, osteoporosis/metabolic bone disease and rehabilitation, all need to work together. Only by presenting a united front will policy makers and politicians heed this message.

In 2020 we will enter the WHO "Decade of Healthy Ageing" which sets out 10 priorities to improve the global care of older people.(13) The priorities include themes of collecting better global data on healthy ageing, promoting research that addresses the needs of older people, developing global networks, and making the economic case for investment in healthy ageing. These priorities are entwined with those of the FFN global Call to Action. This is the time. Our ability to meet the challenges of fragility fracture care in the future, will depend on the strategies we implement now.

1. TARN: Major Trauma in Older People 2017. 2017 Mar.

2. Johnell 0, Kanis JA. An estimate of the worldwide prevalence and disability associated with osteoporotic fractures. Osteoporos Int. 2006 Dec $1 ; 17(12): 1726-33$.

3. Griffin XL, Parsons N, Achten J, Fernandez M, Costa ML. Recovery of healthrelated quality of life in a United Kingdom hip fracture population: the Warwick Hip Trauma Evaluation - a prospective cohort study. The Bone and Joint Journal. 2015 Mar;97-B(3):372-82.

4. Hernlund E, Svedbom A, Ivergård M, Compston J, Cooper C, Stenmark J, et al. Osteoporosis in the European Union: medical management, epidemiology and economic burden. Arch Osteoporos. Springer London; 
2016;8(1-2):136.

5. Court-Brown CM, Duckworth AD, Clement ND, McQueen MM. Fractures in older adults. A view of the future? Injury. 2018 Dec;49(12):2161-6.

6. Lems WF, Raterman HG. Critical issues and current challenges in osteoporosis and fracture prevention. An overview of unmet needs. Ther Adv Musculoskelet Dis. 2017 Dec;9(12):299-316.

7. Fernandez MA, Arnel L, Gould J, McGibbon A, Grant R, Bell P, et al. Research priorities in fragility fractures of the lower limb and pelvis: a UK priority setting partnership with the James Lind Alliance. BMJ Open. 2018 Oct 3;8(10):e023301.

8. Osteoporosis: fragility fracture risk. NICE CG146. 2017 Feb.

9. Gordon CM, Zemel BS, Wren TAL, Leonard MB, Bachrach LK, Rauch F, et al. The Determinants of Peak Bone Mass. J Pediatr. 2017 Jan;180:261-9.

10. Harvey NCW, McCloskey EV, Mitchell PJ, Dawson-Hughes B, Pierroz DD, Reginster J-Y, et al. Mind the (treatment) gap: a global perspective on current and future strategies for prevention of fragility fractures. Osteoporos Int. 2017 May;28(5):1507-29.

11. The National Hip Fracture Database [Internet]. [cited 2015 Jan 28]. Available from: http://www.nhfd.co.uk

12. Dreinhöfer KE, Mitchell PJ, Bégué T, Cooper C, Costa ML, Falaschi P, et al. A global call to action to improve the care of people with fragility fractures. Injury. 2018 Aug;49(8):1393-7.

13. World Health Organization: Decade of Action on Healthy Ageing [Internet]. [cited 2019 Mar 9]. Available from: https://www.who.int/ageing/10priorities/en/ 